\title{
Direitos de propriedade em aldeamentos e colônias agrícolas na Amazônia (1840-1880)
}

\author{
Francivaldo Alves Nunes[1]
}

\begin{abstract}
Resumo
A proposta deste artigo é compreender como os agentes públicos concebiam a concessão de direitos de propriedade sobre a terra nos aldeamentos de índios e nas colônias agrícolas na Amazônia do século XIX. A concessão do direito de utilização da terra, ou seja, a garantia legal da permanência de índios e colonos em seus direitos à utilização dos recursos fundiários afetados aos aldeamentos e às colônias agrícolas, estava condicionada à ocupação regular da terra e à agricultura. Apoiados nos relatórios e nas correspondências da administração provincial, mostraremos que os aldeamentos e as colônias eram representados como espaços modelares de socialização, em que se observa a política governamental de institucionalização de direitos de propriedade sobre a terra, subordinada a uma disciplina do trabalho agrícola. Essa relação é representada como uma estratificação social, reconhecendo à partida aos colonos o estatuto social de agricultores autônomos, detentores de propriedade individual ainda que condicionada, e aos índios o de trabalhadores em aprendizado na terra coletiva gerida por um diretor de aldeamento. Por último, identificamos exemplos de dificuldades de implantação, conflito e resistência a essa disciplina, representadas nos discursos oficiais.
\end{abstract}

Palavras-chave: aldeamentos de índios; colônias agrícolas; direitos de propriedade.

Property rights in agricultural settlements and colonies in the Amazon (1840-1880)

Abstract

This paper aims to understand the public agents' concepts concerning the grant of property rights in land to Indian settlements and to settlers in agricultural colonies in nineteenth century Amazonia. The grant of the right to use the land, that is, the legal warranty of the permanence of the Indians' and the settlers' rights to use the landed resources allocated to the settlements and the colonies, was contingent on the regular use of the land and on agricultural activities. Based on the province administration's reports and correspondence, we will show that both the Indian settlements and the agricultural colonies were represented as model spaces for socialization, which display a governmental policy of institutionalizing property rights in land subject to the discipline of agricultural work. This relationship is represented as one of social stratification, by which the settlers were afforded the social status of autonomous farmers, who were granted individual albeit conditional property rights to begin with, whereas the Indians were allocated the status of apprentice labourers in collective land, managed by an appointed settlement director. Finally, we give some instances of struggling implementation, conflict and resistance to that discipline, as represented in official discourses.

Keywords: Indian settlements; agricultural colonies; property rights.

\section{Les droits de propriétédans lesétablissements autochtones et les colonies agricoles de l'Amazonie(1840-1880)}

\section{Résumé}

Le but de cet article est de comprendre comment les fonctionnaires ont conçu l'octroi de droits de propriété sur la terre dans les colonies des indiens et des colonies agricoles dans le XIX ${ }^{\mathrm{e}}$ siècle dans l'Amazonie. L'octroi du droit d'utiliser la terre, à savoir la garantie légale de la permanence des indiens et des colons dans leurs droits d'utilisation des ressources en terres dans les villages touchés et les colonies agricoles, a été soumis à l'occupation régulière de la terre et de l'agriculture. Se fondant sur les rapports et la correspondance de l'administration provinciale, nous montrons que les établissements autochtones et les colonies agricoles étaient représentées comme des espaces de modèles de socialisation, où il y a une politique du gouvernement de l'institutionnalisation des droits de propriété sur la terre, sous la réserve d'une discipline du travail agricole. Cette relation est représentée comme une stratification sociale, reconnaissant les colons en partance pour le statut social des agriculteurs autonomes, les détenteurs de propriétés individuels, même si conditionné, et l'apprentissage dans les travailleurs indiens dans la terre collective gérée par un directeur du village. Enfin, nous identifions des exemples de difficultés de mise en œuvre, les conflits et la résistance à cette discipline, représentés dans les discours officiels.

Mots-clés: resorts des indiens ; colonies agricoles ; les droits de propriété.

\section{Derechos de propiedad en los asentamientos indígena y colonias de la Amazonía (1840-1880)}

\section{Resumen}

El propósito de este artículo es entender cómo los funcionarios públicos conciben la concesión de derechos de propiedad sobre la tierra en los asentamientos de indios y colonias agrícolas en Amazonsiglo XIX La concesión del derecho de uso de la tierra, es decir, la garantía legal de permanencia de los indios y los colonos en sus derechos de uso de los recursos de tierras a los pueblos afectados y colonias agrícolas, fue objeto de ocupación regular de la tierra y la agricultura. Sobre la base de los informes y correspondencia de la administración provincial, se muestra que los asentamientos y colonias han estado representados de espacios modelo de socialización, donde hay una política del gobierno de la institucionalización de los derechos de propiedad sobre la tierra, con sujeción a una disciplina de trabajo agrícola. Esta relación se representa como una estratificación social, el reconocimiento de los colonos que salen a la condición social de los agricultores autónomos, titulares de propiedad individual, aunque acondicionado, y el aprendizaje de los trabajadores indios en tierra colectiva gestionado por un director de la aldea. Por último, se identifican ejemplos de dificultades de ejecución, el conflicto y la resistencia a esta disciplina, representadas en los discursos oficiales.

Palabras-clave: resorts de indios; colonias agrícolas; los derechos de propiedad 
A s questões referentes às formas de utilização da terra na Amazônia ocupam um lugar privilegiado nos estudos históricos. No entanto, ou são associadas às experiências secundárias de produção, quando analisadas no contexto da economia brasileira, ou compreendidas de forma regionalizada ou até isolada dos interesses e projetos nacionais. Caio Prado Júnior explica que, em razão de a estrutura econômica do país ter sido erguida sobre os alicerces da dependência em relação aos ditames do mercado internacional, e não sobre as bases de um projeto para a formação de uma nação autônoma diante de seus colonizadores, as práticas de plantio e extração na Amazônia aparecem como atividades econômicas secundárias, pois não tinham por objeto o comércio externo, não se caracterizando como uma economia colonial, mas sim acessória e complementar (Prado Júnior, 1964, p. 113). Isso leva o autor a concluir que os programas de colonização estavam muito mais associados ao desenvolvimento de uma economia de exploração predatória dos recursos naturais da região do que ao de uma produção sustentada no povoamento e na constituição de propriedades.

Para Júlio Bentivoglio (2007, p. 49), essa posição de economia complementar era justificada quando se observavam os debates parlamentares e os registros do Ministério da Fazenda entre os anos de 1850-1851, para quem a Amazônia não se apresentava como espaço prioritário de investimento na produção agrícola, uma vez que suas rendas advinham da economia de extração de produtos florestais. Mesmo nos estudos mais localizados de Ernesto Cruz (1958, p. 28), as atividades colonizadoras foram analisadas para explicar o crescimento das rendas públicas e o abastecimento dos centros urbanos regionais, sem apresentar maiores preocupações sobre os mecanismos de acesso e controle sobre a terra.

A preocupação que envolve a constituição de propriedades pela via do cultivo foi observada nos estudos de Rafael Chambouleyron (2010, p. 121) para o século XVII, para quem o envolvimento de indígenas em atividades econômicas, consideradas importantes pela Coroa portuguesa, como o plantio do tabaco, da cana-de-açúcar e do cacau, se constitui em estratégia de arregimentação de mão de obra local e ocupação produtiva das terras amazônicas.

Localizada ao norte do Brasil e no século XIX formada pelas províncias do Grão-Pará e do Amazonas, não há dúvidas de que, nas décadas de 1840 a 1880, a Amazônia foi projetada como espaço estrategicamente pensado para desenvolver a economia brasileira por meio da criação de programas de colonização vinculados à expansão das áreas produtoras de alimentos e do aumento do número de trabalhadores rurais. Segundo Eugênia Égler, a exuberância da mata virgem encontrada nas terras amazônicas teria impressionado os governantes, "fazendo-os cogitar em transformar a fictícia uberdade das terras florestais num manancial para abastecimento [dos núcleos urbanos]" pela via do cultivo (Égler, 1961, p. 529). Diante desse cenário de idealização e projeto, nossa proposta é analisar os discursos, principalmente de gestores públicos, 
sobre as colônias agrícolas e os aldeamentos de índios como ações vinculadas ao desenvolvimento da agricultura e do povoamento em um momento em que se busca instituir uma política de ocupação de terra e de aproveitamento da mão de obra indígena promovida durante o Império brasileiro (1820-1880).

Os discursos construídos em torno desses programas e que se materializaram na criação de núcleos agrícolas de colonos europeus e de aldeamentos de índios expressam posicionamentos fundamentados pelos interesses dos diversos agentes envolvidos, que adotam e expressam a carga histórica dos temas e das questões dos quais tratam (Bakhtin, 2006, p. 56). Ou seja, a fala dos agentes públicos em relatórios e correspondências oficiais se constitui em evento social, não se caracterizando como um acontecimento contido em uma linguística abstrata, nem algo originado da consciência subjetiva desses indivíduos, sendo antes resultado de um processo de interação com o meio social cujas representações refletem no momento mesmo em que procura modelá-las.

\section{Não há dúvidas de que, nas décadas de 1840 a 1880, a Amazônia foi projetada como espaço estrategicamente pensado para desenvolver a economia brasileira}

Assim, as vinculações entre Estado e colonização não serão aqui pensadas apenas como reflexo da crise escravista provocada pelo fim do tráfico de escravos, mas como fruto de relações entre projetos e grupos sociais diferentes e divergentes, refletindo interesses regionalizados. Assim, o ato de colonizar está revestido da ideia de domínio sobre as terras e as populações (Laranjeiras, 1983). Trata-se, portanto, de se entender colonização no sentido de ocupação territorial, combinada não só com a ideia de desenvolvimento de uma atividade econômica e de controle sobre o espaço e os recursos, mas também de controle sobre as populações e os hábitos. Conhecer o processo de implantação dos programas de colonização implica compreender os significados construídos em torno desses espaços e dessas populações. Isso exige analisar os interesses quanto às normas que determinavam as formas de ocupação, os critérios de escolhas dessas áreas, os locais destinados às atividades agrícolas, as modalidades de concessão de direitos sobre a terra, os critérios para sua distribuição e as exigências para a aquisição, a estabilização e a progressão nesses direitos nas áreas de colonização, relacionando-os com os valores e os significados atribuídos aos sujeitos visados, isto é, colonos e índios.

Consideramos como direitos de propriedade "os direitos socialmente reconhecidos a uma pessoa de realizar ações com um recurso, de extrair rendimentos dele e de autorizar ou proibir a terceiros o seu uso" (Santos, 2012, p. 282), e, portanto, fundamentalmente como relações, resultando no "conjunto de elementos relacionados con las formas diarias de acceder a los recursos, con las prácticas diarias de la distribución social de la renta", e ainda as 
interpretações que são construídas para legitimar esse conjunto de relações e gerar consentimento em torno delas (Congost, 2007, p. 15). Isso implica a compreensão da propriedade como resultado não apenas do consenso, da cultura e dos constrangimentos institucionais, mas também das relações de poder e das disputas sobre a legitimidade das apropriações, incluindo as possibilidades de reconfigurar nas práticas as relações de propriedade instituídas pelo Estado. Por outro lado, a distribuição dos direitos de propriedade constitui um parâmetro fundamental de estratificação social das pessoas e dos grupos e de definição de identidades sociais; particularmente, nas sociedades rurais, os direitos de propriedade que incidem sobre a terra (Santos, 2012, p. 282-283).

É nossa hipótese diretora que a instituição dos direitos de propriedade nos espaços de colonização (aldeamentos e colônias agrícolas) está associada à busca do exercício de dominação e do controle social e territorial pelo Estado imperial brasileiro. Essa dominação é exercida pela inculcação de valores pela atividade agrícola, o que significa pensar a constituição da propriedade como elemento regulador, disciplinador das relações das pessoas entre si e com o espaço. Por outro, o Estado se apresenta como instituição protetora do direito de propriedade, uma vez que cria legislação para esses espaços, sendo os agentes públicos responsáveis por sua implantação. Essa hipótese leva a pensar os modos de instituição de direitos de propriedade sobre a terra nos aldeamentos de índios e nas colônias agrícolas na ótica da capacidade de introdução de novos valores, como o apego à terra e a valorização do trabalho regular. Em outras palavras, significa compreender a legitimação dos direitos de propriedade pela autoridade pública em função do exercício de uma atividade econômica (a agricultura), justificada por sua capacidade disciplinadora tanto quanto produtiva. Essa faceta das ações colonizadoras na Amazônia como propulsora de medidas moralizadoras, no caso das províncias do Pará e do Amazonas, fica mais bem evidenciada quando se analisa a atividade econômica defendida para esses espaços, a agricultura, em relação com a definição de direitos de propriedade.

Trabalhamos na perspectiva de que as ações desses indivíduos e grupos no interior dos núcleos coloniais e aldeamentos não devem ser pensadas de forma isolada da legislação criada em torno dos programas de colonização, mas se constitui em conformidade ou em oposição às normas impostas pelas autoridades, dependendo dos interesses de cada grupo. A compreensão e a apropriação que os colonos e indígenas farão dos sistemas normativos nos quais estão inseridos serão elementos fundamentais para a definição das práticas e estratégias de sobrevivência. O processo de implantação e consolidação das áreas de colonização reflete, portanto, a relação entre as legislações pensadas para administrar esse espaço e os modos de vida dos colonos e dos índios aldeados, constituindo "um conjunto complexo ao mesmo tempo de receitas técnicas e de costumes" (Bloch, 2001, p. 135). 


\section{Considerações preliminares dos agentes públicos}

Sem população não se formam, não se enriquecem, nem se sustentam o Estado, e se uma província há no Brasil, que mais necessite de braços, e braços laboriosos, é seguramente o Pará. Esta verdade é para mim dogmática. ${ }^{2}$

A expressão em epígrafe, do presidente do Grão-Pará Antonio de Miranda e que dá o mote a um longo relatório de sua administração apresentado ao parlamento provincial em 15 de agosto de 1840, expressa a convicção da necessidade de aumento da população dedicada ao trabalho agrícola. $\mathrm{O}$ fragmento abria longas considerações convergindo na defesa da implantação de colônias agrícolas e aldeamentos como medidas que facilitassem quer a entrada e principalmente a acomodação de colonos estrangeiros, quer o aproveitamento da potencial mão de obra indígena, que estaria dispersa pelas terras de floresta da região.

Um ano depois dessas declarações, o ministro dos Negócios do Império, Candido de Araújo Vianna, censurava a contradição do governo brasileiro pela ausência de ações articuladas que envolvessem o povoamento, o desenvolvimento agrícola e a constituição de propriedades regulares e produtivas. Estava-se também em um momento de debate político sobre a necessidade de criar uma legislação que regulamentasse o trabalho indígena e as formas de acesso à terra, que viria a ser aprovada em 1845 (Regulamento das missões) e 1850 (Lei de terras) A fala do ministro não apenas evocava os princípios que deveriam nortear as ações colonizadoras do Império, mas chamava a atenção para o desequilíbrio de investimento entre os recursos voltados para a construção de colônias agrícolas e de aldeamentos de índios: "dispendiosas diligências para a aquisição de braços livres eram efetivadas, quando até então nenhuma ação mais consistente havia sido efetivada para tornar úteis [braços] que já [existiam] no país". Acrescentava que, no caso dos índios, "não se tratava apenas de tornar úteis braços improdutivos, mas porém prejudiciais e devastadores à produção, à riqueza e à prosperidade da nação". O proveito que se deixava de tirar de muitos terrenos que se achavam "baldios pelo único receio das incursões dos selvagens", as plantações e edifícios que esses grupos tinham "estragados, inutilizados e arrasados pelo seu comportamento indolente e feroz", a perda das vidas de colonos trabalhadores "sacrificados por conta de sua ferocidade", a destruição e morte de outras tribos que ocorriam "nas contínuas guerras em que andavam as diferentes populações indígenas" seriam para o ministro consideráveis prejuízos para o Estado, justificando uma

2 Discurso recitado pelo excelentíssimo senhor doutor João Antonio de Miranda, presidente da província do Pará, na abertura da Assembleia Legislativa Provincial no dia de 15 de agosto de 1840. Pará: Typographia de Santos e Menos, 1840. p. 60. Disponível em: <http://brazil.crl.edu/bsd/bsd/u990/>. Acesso em: 12 mar. 2013. 
atuação mais consistente de controle sobre esses grupos, que deveria encontrar no governo ao menos tanta preocupação quanto a colonização estrangeira. ${ }^{3}$

Ao que tudo indica, as críticas de Candido de Araújo Vianna, que ocupava uma das principais pastas ministeriais, eram compartilhadas por outros ministros. Em 1846, pouco depois de publicado o Regulamento das missões, o ministro Joaquim Marcellino de Brito assimilava colônias agrícolas e aldeamentos de índios a ações de um mesmo projeto, devendo atuar nas regiões do país em que a presença de populações indígenas fosse significativa. No caso da província do Grão-Pará, o ministro entendia que, como ações conjuntas, deviam partir de um mesmo interesse, ou seja, promover o povoamento, a consequente ocupação da terra e a constituição de pequenas propriedades. Nesse caso, o ministro advertia: "muito convinha aproveitar o grande recurso dos indígenas para povoá-la associado à criação de espaços para recebimentos de colonos estrangeiros que desejassem ocupar estas terras"; sendo os índios importantes, por serem "nascidos e criados nestas regiões [e] afeitos a seu clima", e os imigrantes por terem "experiência com o cultivo da terra e com os cômodos da vida civilizada". ${ }^{4}$

Em 1857, já aprovados a Lei de terras e o Regulamento das missões, o então inspetor-geral de Terras Públicas do Pará, João Martins da Silva Coutinho, responsável pela fiscalização dos programas de colonização, reafirmava parte dos discursos anteriores com base na nova legislação. No caso, defendia que, para fazer cessar a carestia de alimentos que tomava conta dos mercados da capital e das cidades interioranas da região amazônica, o governo devia não lançar mão apenas da colonização estrangeira e dos núcleos agrícolas assim criados. Em uma referência aos grupos indígenas, dizia que era inevitável tirar proveito do grande número de indivíduos que se encontravam dispersos pela província e direcioná-los para o campo do trabalho regular e lucrativo, possível apenas com a ocupação intensiva da terra e dos braços aglomerados em aldeamentos. ${ }^{5}$

\section{Localização, formas de acesso e controle do território}

Uma primeira questão a observar quando se atenta para os discursos dos agentes públicos é a relação entre os locais de estabelecimento dos aldeamentos e colônias agrícolas, sua distribuição na região amazônica e a forma de acesso à terra percebida como adequada. Embora se observe a defesa da arregimentação de mão de obra indígena e da imigração estrangeira associada ao aumento

\footnotetext{
${ }^{3}$ Relatório do ano de 1841 apresentado à Assembleia Geral Legislativa na 1 a sessão da $5^{a}$ legislatura pelo ministro e secretário de Estado dos Negócios do Império Candido José d’Araújo Viana. Rio de Janeiro: Typografia Nacional, 1843. p. 29. Disponível em: <http://brazil.crl.edu/bsd/bsd/u1712/>. Acesso em: 12 mar. 2013. ${ }^{4}$ Relatório do ano de 1846 apresentado à Assembleia Geral Legislativa na 4a sessão da 6a legislatura pelo ministro e secretário de Estado dos Negócios do Império Joaquim Marcellino de Brito. Rio de Janeiro: Typografia Nacional, 1847. p. 31-31. Disponível em: <http://brazil.crl.edu/bsd/bsd/u1718/>. Acesso em: 12 mar. 2013.

${ }^{5}$ Relatório do ano de 1857 apresentado a Assembleia Geral Legislativa na $2^{a}$ sessão da $10^{a}$ legislatura pelo ministro e secretário de Estado dos Negócios do Império marquês de Olinda. Rio de Janeiro: Typographia Universal de Laemmert, 1858. Anexo: Relatório da Repartição Geral de Terras Públicas. p. 75. Disponível em: <http://brazil.crl.edu/bsd/bsd/u1730/>. Acesso em: 12 mar. 2013
} 
produtivo de alimentos, parece-nos que, para as terras amazônicas, prevalecem questões articuladas à necessidade da sedentarização do povoamento e da constituição de pequenas propriedades, ou seja, mais voltadas para a transformação do índio em colono e do imigrante em lavrador proprietário, como facetas da colonização e do controle do território.

No caso dos aldeamentos, isso fica evidente quando observamos os critérios de escolha do Alto Rio Negro, afluente da margem esquerda do rio Amazonas como um dos espaços mais adequados para implantação de aldeias coloniais. Nesse local, as atividades missionárias responsáveis por convencer os índios a se estabelecerem nos aldeamentos deviam abranger toda a circunvizinhança, ou seja, o rio Issana, no caso dos índios uaupés, oferecendo a vantagem de se levantar uma povoação em um dos pontos de fronteira com a antiga República de Nova Granada, atual Colômbia. A criação de missões nessa região também se justificava por não se observar aí a presença de colonos. ${ }^{6}$ Os mesmos critérios eram utilizados para a região de fronteira de Tabatinga, território entre a República do Peru e Nova Granada, ficando ela próxima ao rio Içá, por onde a experiência dos anos anteriores de colonização portuguesa mostrou que foram realizados diferentes descimentos de índios. Sendo ainda recomendado "que não fosse sem propósito indicar as imediações da vila de Borba no rio Madeira, e igualmente as do rio Jutaí". ${ }^{7}$ No caso desta última região, ficava evidente a ideia de que parte da população indígena ocupante desse território já havia acumulado a experiência de contato com os colonizadores, o que podia facilitar a reunião desses indígenas em aldeamentos.

A preocupação das autoridades estava em reunir grupos indígenas dispersos pelas terras de floresta em razão da vida nômade. A ideia inicial que se extrai das falas dessas autoridades é a aposta de que a atividade agrícola levaria à sedentarização, requisito inicial para o acesso à terra e a constituição de propriedades em regiões até então concebidas como devolutas ou incultas. Nesse aspecto, o reconhecimento ou a formalização oficial do direito de se apropriar da terra está condicionado a uma forma específica de sua utilização.

Por outro lado, os exemplos anteriores das missões do Alto Rio Negro, Tabatinga, rio Madeira e rio Jutaí mostram que os direitos de propriedade coletivos instituídos nos aldeamentos são utilizados como estratégia, no caso das regiões de fronteira com outras nações, para assegurar a implantação de vilas e povoados, garantindo, assim, o controle do território pelas autoridades do Brasil; para além de se evitarem os conflitos com colonos, principalmente quando estes pudessem tentar ocupar os aldeamentos em busca de mão de obra para suas propriedades, colocando em risco a empreitada colonizadora. Nesse caso, os direitos de propriedade do aldeamento são acionados para a supressão de uma demanda então comum na região, ou seja, a ocupação de áreas consideradas inóspitas e não povoadas. Por outro lado, a concentração

\footnotetext{
${ }^{6}$ Discurso recitado pelo excelentíssimo senhor doutor João Antonio de Miranda, presidente da província do Pará, na abertura da Assembleia Legislativa Provincial no dia de 15 de agosto de 1840. Pará: Typographia de Santos e Menos, 1840. p. 62-63. Disponível em: <http://brazil.crl.edu/bsd/bsd/u990/>. Acesso em: 12 mar. 2013. 7 Ibidem, p. 63. Disponível em: <http://brazil.crl.edu/bsd/bsd/u990/>. Acesso em: 12 mar. 2013
} 
das populações indígenas previamente dispersas em um mesmo território facilitava a ampliação das áreas de ocupação por proprietários de terras da região, que podiam expandir os limites de suas propriedades.

Em 9 de julho de 1843, o vigário da Barra do Rio Negro, João Antônio Alves, em cumprimento de ordens e instruções que recebeu da presidência do Pará, comunicou que no dia 30 de junho do mesmo ano se dirigiu a uma povoação, "vulgo maloca, de gentios Muras", no rio Jauanacá, na qual havia em torno de 400 almas. Comunicava a necessidade "de erigir-se uma igreja a fim de chamar as hordas que [existiam] nos lagos de Juruá, Momory e Query-Mery”, pois os índios "realizavam comércio com alguns regatões [comerciantes] e agricultores", o que podia contribuir para o arregimento em aldeias coloniais. ${ }^{8}$ Ainda com essa expectativa, defendia a criação de duas ou três missões na comarca de Cametá, onde, segundo constava dos registros governamentais, existiam quatro tribos: as dos jacundás, cupelobos, taxinas e carambus, que desenvolviam um intenso comércio com os mercadores daquela cidade. Uma devia ser fundada nas margens do Remansão na embocadura do rio Taboca, tributário do Tocantins, que se destinaria à catequese dos jacundás; outra, em São João do Araguaia ou suas imediações para os cupelobos que habitavam as matas próximas ao presídio de São João do Araguaia; e a terceira na Mauoquary no rio Pacajás, destinada especialmente aos carumbus. ${ }^{9}$

\section{A preocupação das autoridades estava em reunir grupos indigenas dispersos pelas terras de floresta em razão da vida nômade}

A vantagem desses locais em relação às áreas de fronteira, por exemplo, era a de que parte da população indígena já havia acumulado a experiência de contato com os colonizadores portugueses e jesuítas. E, nesse caso, a reunião dos indígenas em aldeamentos, a promoção do trabalho agrícola e a aceitação de padrões de direito sobre a utilização da terra poderiam ser facilitadas.

De acordo com Roberto Santos (1980, p. 89), as experiências de implantação de colônias agrícolas na Amazônia, após a Independência, teve seu início com os empreendimentos da empresa do barão de Mauá, a companhia de Navegação e Comércio do Amazonas, em 1854. Por imposição do governo, em troca de favores e privilégios de navegação, a empresa teria introduzido 1.061 colonos portugueses naquele ano e, pouco depois, cerca de 30 chineses. No caso, havia fundado para seu assentamento as colônias Mauá e Itacoatiara. A

\footnotetext{
${ }^{8}$ Discurso recitado pelo excelentíssimo senhor desembargador Manoel Paranhos da Silva Vellozo, presidente da província do Pará, na abertura da primeira Sessão da quarta Legislatura da Assembleia Provincial no dia 15 de agosto de 1844. Pará: Typographia de Santos \& Menores, 1844. p. 17. Disponível em: <http://brazil.crl.edu/ bsd/bsd/503/ . Acesso em: 12 mar. 2013.

${ }_{9}^{9}$ Ibidem, p. 18-19. Disponível em: <http://brazil.crl.edu/bsd/bsd/503/z. Acesso em: 12 mar. 2013.
} 
primeira nas Lages, a nove milhas $(14,48 \mathrm{~km})$ abaixo de Manaus, e a outra no município de Serpa.

Outro empreendimento dessa natureza foi a vinda de colonos norte-americanos pouco após a Guerra de Secessão, quando se criava a expectativa de uma grande corrente de imigração para o Brasil no Sul dos Estados Unidos, por causa dos desdobramentos desse conflito (Clark, 1998, p. 39). No caso, a introdução de norte-americanos na Amazônia não teria ultrapassado, porém, 160 a 200 imigrantes, assentados a alguns quilômetros da cidade de Santarém, no oeste do Pará, construindo a colônia Bom Gosto entre 1866 e 1867 (Santos, 1980, p. 126).

Em 1871, em virtude da autorização conferida na Lei provincial $\mathrm{n}^{0} 676$, de 22 de setembro daquele ano, que autorizava a administração a solicitar do governo imperial a concessão de seis léguas (366 Km) de terra para ser aplicada a colonização, ${ }^{10} \mathrm{o}$ dr. Abel Graça, presidente do Pará, solicitou a concessão dessas terras na estrada de Bragança, no nordeste do Pará, nos termos da Lei Geral no 514, de 28 de outubro de 1814, que previa em seu artigo 16 a concessão de terras para a colonização. Concedidas em 1873, no ano seguinte o governo provincial dava por completo o serviço de medição e demarcação em 116 lotes de terrenos, ocupando uma área de mais de uma légua quadrada (6,6 $\mathrm{Km}) .{ }^{11}$ Somente em 1875 registra-se a chegada dos primeiros colonos para ocupar os lotes então demarcados, inaugurando o primeiro núcleo agrícola na zona Bragantina, distante seis léguas ( $366 \mathrm{Km}$ ) de Belém, no caso a colônia Benevides, como passaria a ser chamada.

Enquanto na localização dos aldeamentos as regiões de fronteira e as áreas devolutas e inóspitas surgem como os espaços adequados para a colonização indígena, no caso dos núcleos coloniais duas questões parecem ter predominado na escolha das áreas para sua implantação: a necessidade de abastecimento dos centros urbanos e o desenvolvimento de novas técnicas de cultivo. Se, por um lado, esse tipo de estabelecimento partilhava dos mesmos interesses dos aldeamentos, ou seja, a produção de alimentos e o povoamento, por outro o padrão de direitos de propriedade transferidos individualmente para os colonos, associados à constituição de pequenas propriedades de terras a serem ocupadas por imigrantes, era bem mais amplo do que o dos transferidos para os índios nos aldeamentos. Os discursos previam que esses espaços seriam capazes de desenvolver novas técnicas de cultivo que melhor aproveitassem o solo, superando as experiências locais de cultivo com rotação de culturas e a agricultura itinerante, que ocupava a cada ciclo de cultivo novas terras e constantemente abria novas fronteiras de ocupação, que em muitos casos escapavam ao controle territorial dos agentes públicos.

\footnotetext{
${ }^{10}$ Relatório apresentado à Assembleia Legislativa Provincial na primeira sessão da $18^{a}$ legislatura em 15 de fevereiro de 1872 pelo presidente da província, dr. Abel Graça. Pará: Typographia do Diário do Gram-Pará, 1872. p. 58. Disponível em: <http://brazil.crl.edu/bsd/bsd/537/>. Acesso em: 12 mar. 2013.

"Relatório apresentado com que excelentíssimo senhor doutor Guilherme Francisco Cruz $3^{\circ}$ vice-presidente passou a administração da província do Pará ao excelentíssimo senhor doutor Pedro Vicente de Azevedo em 17 de janeiro de 1874. Pará: Typografia Diário do Gram-Pará, 1874. p. 13. Disponível em: <http://brazil.crl.edu/bsd/ bsd/u1224/>. Acesso em: 12 mar. 2013.
} 


\section{Direitos de propriedade, valor moral e controle social}

Os espaços amazônicos anteriores à introdução de projetos colonizadores são representados como locais sem indústria agrícola, o que era explicado pela abundância de meios para garantir os recursos necessários à sobrevivência sem necessidade de transformação desse espaço natural. Essa situação faria, portanto, do homem amazônico um consumidor dos recursos que as florestas prodigalizavam sem grande esforço produtivo. A superação do atraso apontado pela autoridade provincial passaria pela criação de uma agricultura científica, pois se acreditava que a regeneração da agricultura amazônica viria da pesquisa, da intensificação dos processos produtivos, da adoção de técnicas modernas, de cultivo e tratamento do solo, do ensino técnico agrícola, de infraestruturas de apoio à produção e à comercialização. ${ }^{12}$ Ações só possíveis quando tais valores estivessem introjetados pelas populações locais.

Assegurar a propriedade da terra pelo trabalho agrícola significava estratificar socialmente esses grupos reconhecendo aos colonos o estatuto social de agricultores, detentores de uma amplitude de direitos de propriedade individuais sobre a terra extensa e crescente na medida do cumprimento das expectativas de uso agrícola; e aos índios o de trabalhadores em terra cujos direitos de propriedade residiam no aldeamento e eram geridos por seu administrador, com escassos ou direitos individuais sobre a terra, mas em transição para adquiri-los na medida de sua aquisição de hábitos agrícolas. A aquisição de tal estatuto era determinada não pelos recursos que podiam ser investidos, mas pelos valores adotados ou a adotar, associados ao trabalho e à rentabilização da terra, e evidenciados em suas práticas que cumpriria à administração fiscalizar.

A colonização na Amazônia não podia se dar pela simples exploração econômica ou destruição física dos povos nativos. Os aldeamentos desempenharam um papel estratégico nesse processo. A utilização do trabalho indígena ocorreu não apenas para obtenção de produtos nativos, ou simplesmente de aliados, mas sim como elemento participante da colonização. No caso, tratavase de controlar e preservar o índio por meio de um processo de transformação que visava a arregimentá-lo como trabalhador produtivo e potencial colono.

O balanço das missões criadas ao longo da primeira metade da década de 1840 no Grão-Pará, feito pelo vice-presidente José Maria de Moraes em 1845, evidencia essa questão. Registrava que os bons resultados advinham de missões como a São Joaquim do Rio Branco, onde já se observava uma igreja bem construída e coberta de telha, uma casa que servia de residência para o missionário e 32 indígenas das tribos uapixunas, mucuxis e saparás, os quais se empregavam na cultura de mandioca, milho e cana-de-açúcar. Conforme informações, o número total dos indígenas podia chegar à monta de 1.600 almas, 0 que não significava que todos residissem efetivamente na missão; no entanto,

${ }_{12}$ Relatório do excelentíssimo senhor Angelo Thomaz do Amaral presidente da província do Gram-Pará ao excelentíssimo senhor vice-presidente Olyntho José Meira por ocasião de passar-Ihe a administração da mesma em 04 de maio de 1861. Pará: Typographia de Santos \& Irmãos, 1861. Anexo n. 13. Disponível em: <http://brazil.crl.edu/bsd/bsd/u1006/>. Acesso em: 12 mar. 2013. 
não deviam deixar de visitar frequentemente o aldeamento trazendo consigo objetos de agricultura produzidos em suas malocas, as quais distavam da povoação de três a seis léguas (183 Km a 366 Km), como as de Macuá, Taby, Camati, Majary, Maracá, Santa Rosa e Taramé. Para o vice-presidente, essa ainda não era a condição adequada, pois a pretensão era que os índios desenvolvessem a atividade de cultivo nas terras dos aldeamentos, pois só assim estariam sob a vigilância dos administradores, ao mesmo tempo que se habituariam a ocupar uma mesma terra, cultivar uma mesma área e, consequentemente, construir uma choça (casa). Em suma, levando os índios a sedentarizar-se e a intensificar o uso da terra, ao mesmo tempo que se restringia a superfície total sob seu uso. O hábito de cultivar a mesma terra os levaria a ter maior conhecimento sobre a fertilidade do solo, identificando o que podia ser plantado, e a adequar suas necessidades às condições de cultivo. ${ }^{13}$

No caso dos aldeamentos, a defesa do trabalho agrícola extrapola a dimensão econômica dessa atividade. A percepção da disciplina, moralização e controle ganha contornos claros. O vice-presidente José Maria de Moraes nos aponta que o direito de apropriação da terra nos aldeamentos estaria condicionado ao cumprimento de etapas. Há padrões de direitos para o uso da terra no que se refere ao índio que ocupa regulamente o aldeamento ou aquele que, mesmo visitando as aldeias coloniais, cultivam outras áreas sob seu controle direto; sendo os dos primeiros considerados mais legítimos e superiores aos dos segundos.

Com efeito, a forma como o Regulamento das missões, de 1845, organizava os aldeamentos projetava dois tipos de unidades de produção agrícola: as de cultivo comum e as familiares. O artigo $2^{\circ}, \S 2^{\circ}$, estabelecia que os diretores de índios, além de administrarem as aldeias, geriam a terra do aldeamento e detinham a responsabilidade de distribuição de direitos fundiários aos aldeados, mediante critérios vinculados ao cultivo regular da terra. As atribuições do diretor se estendiam à designação entre as populações indígenas das terras "que [deviam] ficar reservadas para as plantações em comum", assim como "as que [deviam] ficar para as plantações particulares dos índios". O $\$ 7^{\circ}$ do mesmo artigo define a distribuição de objetos, incluindo os instrumentos de plantio, considerando os trabalhos comuns e particulares dos índios. ${ }^{14}$ Para frei Egidio de Gavezio, da missão do Tapajós, a distribuição dessas terras para plantio era importante para os indígenas para que, por meio delas, pudessem produzir o sustento pessoal e o de suas famílias. Não se tratava apenas de evitar que eles vagassem pelas matas em busca de alimentos; a ideia era que se habituassem

\footnotetext{
${ }^{13}$ Discurso recitado pelo excelentíssimo senhor doutor João Maria de Moraes, vice-presidente da provincia do Pará na abertura da segunda sessão da quarta Legislatura da Assembleia Provincial no dia 15 de agosto de 1845. Pará: Typographia de Santos \& Filhos, 1845. p. 26-27. Disponível em: <http://brazil.crl.edu/bsd/bsd/504/> Acesso em: 12 mar. 2013.

${ }^{14}$ Decreto no 426 de 24 de julho de 1845. In: Coleção das leis do Império do Brasil. Rio de Janeiro: Typographia Nacional, 1846. t. VIII, parte II, p. 92. Disponível em: <http://www.camara.gov.br/Internet/InfDoc/conteudo/ colecoes/Legislacao/legimp-31/Legimp-31_10.pdf>. Acesso em: 26 mar. 2013.
} 
ao cultivo regular, à criação de núcleos familiares, entendidos como condições essenciais para a constituição de pequenas propriedades. ${ }^{15}$

As unidades de produção agrícola no interior dos aldeamentos, diante das questões apresentadas por frei Egidio de Gavezio e registadas no Regulamento das missões, apontavam, assim, para tipos de propriedade (coletiva e familiar) nos aldeamentos, diferentes, mas complementares, sendo a experiência do trabalho agrícola disciplinado nas terras coletivas condicionante da concessão de terras para cultivo individual, interpretável como uma sucessão de etapas de aquisição de direitos sobre a terra.

\section{A utilização do trabalho indígena ocorreu não apenas para obtenção de produtos nativos, ou simplesmente de aliados, mas sim como elemento participante da colonização.}

À prática da agricultura é atribuída a tarefa de dinamizar essas etapas e, consequentemente, avançar na concessão de novos padrões de direitos de propriedade. A atividade agrícola é acreditada não apenas como garantia do sustento, com a promoção de meios para produzir a própria manutenção do índio e da aldeia, mas também como inculcadora de costumes, indicando que o direito de controlar se sobrepõe ao de uso e aproveitamento econômico. No fundo, o que se estava objetivando era a criação de condições que permitissem a redução da parcela dos recursos florestais na subsistência das populações aldeadas, pois se acusava a abundância desses recursos de causar o extrativismo e o nomadismo das populações na Amazônia. Indica-se, portanto, uma posição predominante sobre os aldeamentos e que envolvia a concessão de direitos de propriedade: a que o índio fosse retirado das matas, catequisado, ensinado o amor ao trabalho e a propriedade, a respeitar a justiça e as normas sociais "civilizadas", a ser útil a si e à sociedade nacional. Correlativamente, os direitos de propriedade legitimados pelo Estado às populações índias se confinariam às terras atribuídas aos aldeamentos e agricultadas sob a tutela de suas administrações - efetivamente expropriando-as de suas mais amplas áreas tradicionais de apropriação para recoleção e agricultura itinerante, atividades consideradas ilegítimas para a constituição de propriedade.

Nos núcleos coloniais, onde se agregava a ocupação perene das terras em pequenas propriedades, o objetivo era que em um espaço limitado de cultivo se pudesse produzir o suficiente para o consumo e a comercialização, sem que a cada ano fosse necessário ocupar uma nova terra. Mais do que a extensão ou

\footnotetext{
${ }^{15}$ Fala dirigida pelo excelentíssimo senhor conselheiro Jerônimo Francisco Coelho, presidente da província do Gram-Pará à Assembleia Legislativa Provincial na abertura da segunda Sessão ordinária da sexta legislatura no dia $1^{\circ}$ de outubro de 1849. Pará: Typographia de Santos \& Filhos, 1849. p. 82. Disponível em: <http://brazil. crl.edu/bsd/bsd/508/>. Acesso em: 12 mar. 2013.
} 
a valia econômica da terra, a amplitude e a duração dos direitos de propriedade estavam condicionadas à capacidade provada de explorar os recursos fundiários disponíveis pelo colono.

Conforme o Decreto ํㅜㄹ. 2.168, de $1^{\circ}$ de maio de 1858, previsto na Lei de terras de 1850, que estabelecia os regulamentos sobre colônias agrícolas, ${ }^{16}$ três situações deviam ser imediatamente observadas nesses locais, que se configuravam como requisitos iniciais para a concessão de direitos de propriedade aos ocupantes dos lotes de terra: a derrubada da mata, a construção de casa e o plantio. Para assegurar o desenvolvimento dessas ações, o decreto previa alojamentos para os colonos em casas provisórias, enquanto aguardavam a construção de suas moradias definitivas, e o fornecimento de sementes, instrumento de trabalho e mantimentos durante os seis primeiros meses de permanência do núcleo; a entrega de um lote de terra a cada família imigrante medindo um hectare e meio $\left(15.000 \mathrm{~m}^{2}\right)$, a ser escolhido por seu responsável, já demarcado, desmatado e pronto para o cultivo; e o repasse do título provisório de posse, quando do início dos trabalhos de plantio, sendo o definitivo concedido só depois de cinco anos de ocupação efetiva.

Assim, constata-se uma divisão e graduação da transferência dos direitos de propriedade, ou seja, os direitos seriam ampliados, em amplitude e duração, à medida que os colonos fossem superando novas etapas do processo de ocupação e aproveitamento de seus lotes (e com isso ampliando a valia econômica da terra). A extensão das ações que o detentor tinha o direito de executar não estava somente vinculada a seu interesse, mas também condicionada à fiscalização dos órgãos governamentais sobre o cumprimento de suas expectativas de trabalho e valorização.

Para essa questão, que envolve o desenvolvimento de técnicas produtivas, o entendimento era de que estava sob a responsabilidade do imigrante estrangeiro o desenvolvimento e o ensinamento "da melhor arte de cultivo, das sementes mais aproveitadas e das modernas técnicas de plantação". De acordo com o presidente Pedro Leão Velozo, no final da década de 1860 os núcleos agrícolas foram pensados como espaços exemplares de produção, de modo a servir de modelo de como se aproveitaria ao "máximo a terra em porções mínimas de território". ${ }^{17}$ Para o ministro da Agricultura Manoel Alves de Araújo, em 1891, o controle das colônias agrícolas por agentes públicos visava a fazer um acompanhamento direto dos plantios nos núcleos coloniais, de modo a se conhecerem as plantas e sementes que se achavam aclimatadas e o solo a que melhor se adaptariam, as extensões da área agricultável, o proveito colhido pelos agricultores e as formas de manejo do solo. Destacava ainda a importância de se registrarem os tipos de instrumentos agrícolas utilizados, em que diferiam dos

\footnotetext{
${ }^{16}$ Decreto no 2168, de 10 de maio de 1858. In: Coleção das leis do Império do Brasil. Rio de Janeiro: Typographia Nacional, 1858. t. XIX, parte II, p. 16. Disponível em: <http://www.camara.gov.br/Internet/InfDoc/conteudo/ colecoes/Legislacao/1858-pronto/Leis-1858_index02-p1.pdf>. Acesso em: 12 mar. 2013.

17 Relatório com que excelentíssimo senhor presidente da provincia, dr. Pedro Leão Vellozo passou a administração da mesma ao excelentíssimo senhor $1^{\circ}$ vice-presidente, barão do Arary, no dia 9 de abril de 1867. Pará: Typographia de Frederico Rhossard, 1867. p. 19. Disponível em: <http://brazil.crl.edu/bsd/bsd/531/>. Acesso em: 9 abr. 2013.
} 
nacionais, como eram aplicados, assim como a forma de trabalhar a terra. ${ }^{18}$ Considerando essas palavras, que retomavam discursos anteriores de outras autoridades provinciais, pode-se afirmar que a corrente migratória direcionada ao Pará, associada à implantação das colônias agrícolas, visava a combinar o aumento do número de trabalhadores para a lavoura com a garantia do que Lourenço chamou de "agricultura permanente", ou seja, fundada na adubação e nos instrumentos aratórios, evitando a constante ocupação de novas parcelas de floresta com a atividade de derrubada e queimada (Lourenço, 2001, p. 123). Até se admitia a ampliação dos espaços de cultivo, desde que não implicasse o abandono de terras anteriormente cultivadas.

A expectativa do governo brasileiro era de que, diante de um efetivo controle por agentes governamentais, os imigrantes estrangeiros, em sua maioria franceses, italianos e americanos, conhecendo as técnicas de cultivo local, as condições das terras e as sementes cultiváveis, pudessem, a partir da experiência com a atividade agrícola em seus locais de origem, se vadequar às técnicas de plantio, desenvolvendo implementos e estratégias de cultivo superiores às até então usadas na região. Era essa expetativa de inovação agrícola e de aumento da produtividade que legitimava os direitos de propriedade transferidos para esses colonos, condicionados, assim, à verificação dos resultados esperados. Daí a necessidade de que os lotes de terras distribuídos aos colonos, depois de ocupados, sofressem a visita de agentes públicos fiscalizadores, ou a presença de um diretor para administrar a colônia.

\section{Resistências e limitações}

No entanto, os exercícios de aldear índios e conceder lotes de terras em núcleos coloniais para imigrantes europeus parecem ter sido bem mais complicados do que se idealizava em face das realidades sociais práticas que reconfiguravam as relações previstas pela idealização dos projetos.

Um exemplo é a missão de Porto Alegre, localizada no Alto Rio Branco e habitada pelos índios jaricus, apixanas, macuxis, saparás e procutus. Em 1849, encontrava-se sob a direção do missionário padre Antônio Felippe Pereira. Esse missionário ultimamente se esforçava para fazer descer e aldear os índios que viviam na parte superior do rio Catirimani, confluente do mesmo rio Branco e que vinha desaguar nas proximidades da então despovoada freguesia do Carmo. Informava que poucos tinham sido os avanços no trabalho agrícola, conformando essa atividade a alguns pequenos roçados de mandioca, milho e feijão, considerados pouco significativos, pois ainda não seriam suficientes

\footnotetext{
${ }_{18}^{18}$ Relatório do ano de 1881 apresentado à Assembleia Geral na 2a sessão da 18 a legislatura pelo ministro e secretário dos Negócios da Agricultura. Comércio e Obras Públicas Manuel Alves de Araújo. Rio de Janeiro: Typographia Americana, 1882. p. 91. Disponível em: <http://brazil.crl.edu/bsd/bsd/u1967/>. Acesso em: 6 abr. 2013 .
} 
para atender às necessidades do próprio aldeamento. ${ }^{19}$ Informações também eram observadas na localidade de Souzel, onde os índios taconhapés "que existiam no rio Tucuruí, dando princípio à limpeza do sítio demarcado para sua aldeia, procuram novamente as selvas", sem dar continuidade aos trabalhos de cultivo, segundo reclamavam as autoridades religiosas. ${ }^{20}$ Situação semelhante viviam os índios da povoação de São José de Marabitanas, na margem direita do rio Negro, no Amazonas, que, segundo o viajante naturalista alemão AvéLallemant, em 1859, tinham "pequenas plantações sem importância, das quais mal [tiravam] a alimentação diária”, sendo constantes as fugas das aldeias. É ainda o caso dos índios do aldeamento do Carmo, localizado no rio Içana, também no Amazonas, "quando eram chamados ao trabalho de construção nas aldeias, [fugiam] e [escondiam-se] nas nascentes dos igarapés, onde não [era] possível apanhá-los" (Avé-Lallemant, 1980, p. 123). A explicação para a pouca produção estava na dificuldade da diretoria da aldeia em assegurar a permanência dos índios, uma vez que muitos resistiam em cultivar as sementes distribuídas pelo diretor, assim como não aceitavam trabalhar no terreno que era destinado a fazer seu roçado, ou nos serviços de corte da madeira, optando por se embrenharem nas matas.

A atribuição da insuficiência da produção para suprir as necessidades dos próprios aldeados ao uso irregular da terra, sob o ponto de vista da administração dos aldeamentos, para além de responsabilizar os indígenas, legitimava um discurso de negação das formas de produção das populações nativas e superdimensionava a experiência de cultivo pensada por esses agentes públicos como adequada na condição de produção sistemática. Assim, descartava-se a possibilidade de reconhecimento do trabalho indígena fora das aldeias de colonização, principalmente quanto a uma ocupação regular das terras e uma eventual constituição de propriedades. A constatação da resistência dos índios a cultivar as sementes distribuídas pelos diretores e a confinarem-se ao terreno destinado a seu roçado, optando por se embrenhar nas matas e fazer plantios longe da observação de seus diretores, revela a realização de migrações periódicas, buscando a ocupação de áreas com mais recursos. Ao mesmo tempo que quebrava a rotina de trabalho dos aldeamentos, revelava a resistência de padrões de apropriação da terra vinculados à segurança alimentar do grupo. Uma situação não compreendida pelas autoridades ou, se compreendida, então negada.

Outros casos apontam o incômodo de alguns missionários e diretores de aldeamentos com a forma arredia como eram tratados pelos índios, principalmente quando da distribuição de algumas tarefas voltadas para o plantio. É exemplo a missão do Japurá, Içá e Tonantins, afluentes da margem esquerda do Solimões, que se encontrava sob a administração do padre João Martins

\footnotetext{
${ }_{19}$ Fala dirigida pelo excelentíssimo senhor conselheiro Jerônimo Francisco Coelho, presidente da província do Grão-Pará à Assembleia Legislativa Provincial na abertura da segunda sessão ordinária da sexta legislatura no dia $1^{\circ}$ de outubro de 1849. Pará: Typographia de Santos \& Filhos, 1849. p. 79. Disponível em: <http://brazil. crledu/bsd/bsd/508/>. Acesso em: 19 mar. 2013.

${ }^{20}$ Arquivo Público do Estado do Pará (Apep). Ofícios das autoridades religiosas. Belém, cx. 70, de 20/7/1841.
} 
de Nine. Nesse registro, o missionário queixa-se da atitude dos índios que não aceitavam trabalhar em outras tarefas que não fossem a pesca e a coleta. ${ }^{21}$ Situação semelhante era vivenciada nos aldeamentos do rio Tapajós, sobretudo na aldeia de Santa Cruz, com povoação de 300 a 400 índios mundurucus. Em ofício de 28 de outubro de 1848, as autoridades religiosas responsáveis pelos aldeamentos destacavam a indisposição dos índios para com os trabalhos nas aldeias, principalmente os relacionados com o plantio e a construção de casas. ${ }^{22}$ Nos casos mais extremos, os índios não apenas fugiam das condições de trabalho nos aldeamentos, como os atacavam. É o que nos conta a correspondência de 2 de junho de 1852 do vigário interino da vila de Muaná, frei João da Santa Cruz, que relata ao presidente de província que os aldeamentos "nas imediações daquela vila achavam-se sobre $[$ sic] o constante ataque de índios [não especifica quais os grupos], que não satisfeitos em deixar as aldeias, agora tentavam destruí-las".23

\section{No caso dos aldeamentos, a defesa do trabalho agrícola extrapola a dimensão econômica dessa atividade. A percepção da disciplina, moralização e controle ganha contornos claros}

Em 1874, Pedro Vicente de Azevedo afirmou que, na região do rio Capim, muitos índios vinham sendo utilizados indevidamente na extração de óleo de copaíba e casca do cravo, o que o levara a defender a organização de uma aldeia colonial para 400 índios tembés, a empregar na plantação de mandioca, milho, arroz e tabaco. Entretanto, a falta de vigilância das autoridades teria feito com que eles voltassem à coleta de especiarias, obrigando o administrador a enviar um missionário para gerir o aldeamento. ${ }^{24}$ Mesmo considerando esses "gêneros de comércio da produção espontânea" importantes para as rendas públicas, o aldeamento não podia se constituir em espaço a se sustentar por essa produção: a manutenção do extrativismo nesses espaços significava também manter as práticas silvícolas de vida, não permitindo a inculcação dos valores agrícolas.

Novamente se observa uma compreensão equivocada, ou um entendimento negado das autoridades de que as atividades nos aldeamentos podiam significar apenas o prolongamento de uma economia tradicional de coleta, caça

\footnotetext{
${ }^{21}$ Fala dirigida pelo excelentíssimo senhor conselheiro Jerônimo Francisco Coelho, presidente da província do Grão-Pará à Assembleia Legislativa Provincial na abertura da segunda sessão ordinária da sexta Legislatura no dia 10 de outubro de 1849. Pará: Typographia de Santos \& Filhos, 1849. p. 80. Disponível em: <http://brazil.crl. edu/bsd/bsd/508/>. Acesso em: 19 mar. 2013.

${ }^{22}$ Apep. Ofícios das autoridades religiosas. Belém, cx. 115, de 28/10/1848.

${ }^{23}$ Ibidem, cx. 154, de 2/6/1852.

${ }^{24}$ Relatório apresentado à Assembleia Legislativa Provincial na primeira sessão da 19a legislatura pelo presidente da província do Pará, excelentíssimo senhor doutor Pedro Vicente de Azevedo, em 15 de fevereiro de 1874. Pará: Typographia do Diário do Gram-Pará, 1874. p. 47. Disponível em: <http://brazil.crl.edu/bsd/ bsd/541/>. Acesso em: 13 mar. 2013.
} 
ou agricultura itinerante que asseguravam o sustento desses grupos. Em face do reduzido espaço no interior do aldeamento, as populações indígenas, em lugar de se conformarem ao confinamento espacial e à intensificação agrícola idealizados, mantinham as atividades tradicionais para obtenção do alimento. No cotidiano, a resistência prática à disciplina agrícola pela economia de caça e coleta, com seu padrão extensivo do uso da terra, mantinha-se como atividade principal de sobrevivência, enquanto a agricultura aldeada se apresentava como possibilidade complementar, subvertendo a lógica colonizadora imposta por diretores e missionários.

Nos núcleos coloniais, as dificuldades de ocupação e permanência nos lotes de terra estavam associadas a diversos fatores, que iam desde o desconhecimento de como lidar com a terra e a floresta, a falta de assistência dos órgãos públicos aos colonos, até os próprios critérios de distribuição dos lotes. Em 1875, o coronel José do Ó de Almeida, que então administrava a colônia Benevides, descreve em correspondência encaminhada à presidência do Pará que o desconhecimento pelos imigrantes dos tipos de plantas que podiam ser cultivadas era o principal obstáculo para o crescimento da produção agrícola, a permanência dos colonos e a consequente ocupação dos lotes. Por outro lado, o desconhecimento da importância de vários produtos que podiam ser extraídos da floresta inviabilizaria seu aproveitamento, visto que muitos desses produtos podiam ser usados na alimentação dos colonos, na construção de casas, no cercamento dos terrenos, assim como outros serviriam para a comercialização, aumentando a renda desses agricultores. ${ }^{25}$

Nas colônias de Itacoatiara e Mauá, o presidente do Amazonas em 1857, Thomaz Antonio do Amaral, fazia uma observação semelhante. Embora admitisse certa prosperidade, pois a colônia já contava com aproximadamente 36 casas, diversas oficinas e 63 colonos, entre portugueses e chineses, ${ }^{26}$ considerava os colonos engajados como incapazes para a lavoura da região, pois muitos desconheciam inclusive a melhor forma de limpeza dos terrenos, no caso a derrubada e a queimada da mata.

Um exemplo modelar é dos imigrantes canadenses instalados em Benevides. Ao presenciar as dificuldades que passavam alguns colonos quando expirava o prazo de instalação de seis meses, durante o qual lhe era fornecida alimentação, resolveram procurar a diretoria da colônia para solicitar que lhes prorrogasse o fornecimento de carne e farinha. A justificativa era que o prazo de atendimento, que estava por terminar, não fora suficiente para permitir uma primeira colheita. ${ }^{27}$ Nesse caso, alegaram que não tinham condições de garantir a alimentação das famílias somente com o que era produzido em seus lotes, por terem chegado ao Pará no final de março e início de abril, na força da estação

${ }^{25}$ Apep. Ofícios da diretoria da colônia Benenvides. Belém, cx. 340 (1874-1879), de 1o/12/1875

${ }^{26}$ Fala dirigida à Assembleia Legislativa Provincial do Amazonas em 10 de outubro de 1857 pelo presidente da provincia, Angelo Thomaz do Amaral. Rio de Janeiro: Typographia Universal de Laemmert, 1858. p. 21. Disponivel em: <http://brazil.crl.edu/bsd/bsd/65/>. Acesso em: 13 mar. 2013.

${ }^{27}$ Comissão de Colonização. Diário de Belém, Belém, p. 1, 22 ago. 1876. 
invernosa. Somava-se ainda a impossibilidade de iniciar os trabalhos de derrubada e queima das matas por causa das chuvas.

Sabemos que receberam parecer favorável ao pedido, mas os agentes públicos faziam algumas ressalvas. Somente deviam ser atendidos os colonos reclamantes que tivessem dado prova de espírito de trabalho, ou seja, já tivessem iniciado o cultivo em seus lotes, uma vez que o período de estada no núcleo era tempo suficiente para executar alguns trabalhos que demonstrassem a intenção de desenvolver a atividade agrícola.

A solicitação dos franceses Flanteau e Wasman não teve o mesmo desfecho. Também ocupantes de terrenos em Benevides, estavam incomodados com os critérios de distribuição dos lotes. No caso, defendiam que os colonos fossem divididos de acordo com sua nacionalidade ou que falassem a mesma língua. ${ }^{28}$ Para uma colônia ocupada por imigrantes de diferentes nacionalidades, ou as dificuldades de convivência que poderiam surgir entre eles não foram uma questão considerada pela administração provincial, ou se tratava de uma atuação estratégica das autoridades para evitar o que Zuleika Alvim chamou de "enquistamentos" (Alvim, 2000, p. 385). Para a autora, o desejo de aglutinação dos imigrantes dentro do Brasil era uma das causas da mobilidade dos colonos, inclusive no interior dos núcleos coloniais, o que não era visto com bons olhos pelas autoridades, temerosas de que esse ajuntamento facilitasse a mobilização para futuras reivindicações.

Esses registros, portanto, não apenas demonstravam algumas das dificuldades enfrentadas pelos colonos, principalmente quanto ao conhecimento da melhor forma de lidar com a terra e a floresta, mas sobretudo um equívoco das autoridades provinciais, que acreditavam que o desenvolvimento agrícola resultaria da concessão de terras para plantio e da capacidade dos imigrantes em transportar para a região as técnicas avançadas desenvolvidas em seus locais de origem, que prontamente seriam adaptadas às condições das terras da Amazônia.

\section{Considerações finais}

Os posicionamentos dos agentes públicos apontam para a construção de um entendimento de objetivos comuns das colônias agrícolas e dos aldeamentos de índios; no entanto, permitem-nos identificar características gerais diferentes quanto ao formato desses espaços. As colônias agrícolas deviam se constituir em espaços para recebimento de imigrantes estrangeiros, para cultivo de pequenos lotes de terra, fiscalizados por agentes públicos para que não desviassem dos caminhos da produção para o consumo e para o comércio, condições para que fossem reconhecidos lavradores proprietários. No caso dos aldeamentos, a reunião de grupos indígenas de uma mesma ou diferentes etnias em aldeia colonial sob a administração de um missionário ou representante do governo provincial não resultaria em uma imediata constituição de posses familiares de

${ }^{28}$ Apep. Ofícios da Comissão de Colonização. Belém, cx. 340 (1874-1879), de 17/1/1876. 
terra, uma vez que os índios estavam ainda em fase de acomodação ao modo de vida sedentário. Ou seja, os aldeamentos se apresentavam como espaços de aculturação inicial em hábitos e costumes agrícolas sedentários, por meio do trabalho coletivo na terra atribuída à aldeia, gerido por sua administração. Uma vez adquiridos, levariam à individualização de pequenas propriedades de terra: a mudança de hábitos, valores e competências levaria idealmente à mobilidade social do índio para outro estatuto hierarquicamente superior, o de colono lavrador e proprietário.

As representações subjacentes a esses projetos e à dicotomia dos tipos sociais visados (colono/índio, civilizado/selvagem) estruturam-se, assim, em torno das oposições estatutárias agricultor autônomo/trabalhador agrícola do coletivo dirigido, proprietário/não proprietário, propriedade individual/ propriedade coletiva. Enquanto esses discursos votavam as colônias a investir os colonos nos primeiros estatutos, a idealização dos aldeamentos visava à transição dos índios dos últimos para os primeiros estatutos: um processo que se representava como civilizacional. Nesse aspecto, o trabalho agrícola é fundamental para efetivar a ideia de que para as terras amazônicas prevaleceram questões articuladas à necessidade da sedentarização do povoamento, da constituição de pequenas propriedades e mais voltadas para a transformação do índio em colono e do imigrante em lavrador proprietário.

Esse cenário é construído da relação direta entre a propriedade da terra e o trabalho agrícola como definidora de uma estratificação e de identidades sociais, reconhecendo aos colonos o estatuto social de agricultores proprietários e aos índios o de trabalhadores em transição para adquiri-lo. Isso se evidencia na forma como os aldeamentos e as colônias agrícolas estavam organizados. Enquanto para os núcleos coloniais agrícolas era estabelecida a ocupação perene das terras em pequenas propriedades, tornadas efetivas em função do uso agrícola, para as aldeias projetavam-se dois tipos de unidades de produção agrícola: as de cultivo comum e as familiares. Essa constituição diversificada levou ao estabelecimento de critérios diferentes de direitos de propriedade, pois a distribuição de direitos fundiários aos índios aldeados estava condicionada a critérios vinculados à aquisição de hábitos e capacidades de cultivo regular da terra, enquanto aos colonos, pressupostos tais hábitos e capacidades, esses direitos eram dados à partida e sua ampliação estava condicionada à capacidade efetiva de executar a exploração dos recursos fundiários disponíveis.

As unidades de produção agrícola no interior dos aldeamentos apontavam, assim, para tipos de propriedade (coletiva e familiar) nos aldeamentos, diferentes, mas complementares, sendo a experiência do trabalho agrícola disciplinado nas terras coletivas condicionante da concessão de terras para cultivo individual, interpretável como uma sucessão de etapas de aquisição de direitos sobre a terra. Aos núcleos coloniais constata-se uma divisão e graduação da transferência dos direitos de propriedade, ou seja, os direitos seriam ampliados na medida em que os colonos fossem superando novas etapas do processo de ocupação. 
O estabelecimento de hierarquias que condicionavam os exercícios de aldear índios e conceder lotes de terras em núcleos coloniais para imigrantes europeus legitimou um discurso de negação das formas de produção das populações nativas e superdimensionou a experiência de cultivo pensada por esses agentes públicos como adequada na condição de produção sistemática, sendo a aquisição do estatuto de proprietário determinada não pelos recursos que podiam ser investidos, mas pelos valores associados ao trabalho e à rentabilização da terra, supostamente adotados ou a adotar. $\mathrm{O}$ entendimento era de que a superação do atraso apontado pela autoridade provincial estava condicionada à criação de uma agricultura que, ao mesmo tempo que estava preocupada em adotar modernos princípios e estratégias de produção, fosse capaz de inculcar nas populações locais os valores associados.

Para além das medidas que deviam assegurar a permanência dos índios nos aldeamentos e dos imigrantes nas colônias agrícolas, ambos tinham uma situação jurídica específica, os primeiros no Regimento das missões de 1845 e os últimos na Lei de terras de 1850, que lhes determinava um lugar político, econômico e social a ser ocupado na estrutura hierárquica do Império brasileiro. No caso dos índios, apesar das perdas, a condição de aldeados lhes permitia o direito à terra, embora bem mais reduzida do que a que fora ocupada por seus antepassados. Quanto ao imigrante, permanecer no interior das colônias agrícolas era garantia mínima de que estavam protegidos por uma legislação, embora o que buscavam de fato era assegurar o sustento pelo cultivo da terra ou outras atividades que melhor satisfizessem suas aptidões ou produzissem maior rendimento. Dentro dessas condições bastante limitadas, restritas e opressivas, manter-se aldeado ou em colônias agrícolas podia significar uma possibilidade de agir para fazer valer esses mínimos direitos que a lei lhes oferecia, incluindo a construção de novas formas de acesso à terra para além da agricultura; situação não muito provável.

A pesquisa em que este artigo se baseia foi realizada durante o estágio de pós-doutorado na Universidade Nova de Lisboa com o apoio da Coordenação de Aperfeiçoamento de Pessoal de Nivel Superior (Capes) sob supervisão do professor doutor Rui Santos, a quem agradeço a leitura e os valiosos comentários. 


\section{Referências bibliográficas}

ALVIM, Zuleika. O Brasil italiano. In: FAUSTO, Boris. Fazer a América. São Paulo: USP, 2000. AVÉ-LALLEMANT, Robert. No rio Amazonas (1859). Belo Horizonte: Itatiaia, 1980. BAKHTIN, Mikhail. Marxismo e filosofia da linguagem. São Paulo: Hucitec, 2006. BENTIVOGLIO, Júlio. Os negócios do Império: a política econômica brasileira no início do Segundo Reinado (1840-1860). Catalão: UFG, 2007.

BLOCH, Marc. A terra e seus homens: agricultura e vida rural nos séculos XVII e XVII. São Paulo: Edusc, 2001.

CHAMBOULEYRON, Rafael. Povoamento, ocupação e agricultura na Amazônia colonial (16401706). Belém: Açaí, 2010.

CLARK, Jorge Uilson. A imigração norte-americana para a região de Campinas: análise da educação liberal no contexto histórico brasileiro. Dissertação (Mestrado em Educação), Unicamp, Campinas, 1998.

CONGOST, Rosa. Tierras, leyes, historia: estudios sobre "La gran obra de la propiedad". Barcelona: Crítica, 2007.

CRUZ, Ernesto. Colonização do Pará. Belém: Conselho Nacional de Pesquisa/Instituto Nacional de Pesquisas da Amazônia, 1958.

ÉGLER, Eugênia. A Zona Bragantina no estado do Pará. Revista Brasileira de Geografia, v. 23, n. 3, p. 527-555, jul./set. 1961.

LARANJEIRAS, Raymundo. Colonização e reforma agrária no Brasil. Rio de Janeiro: Civilização Brasileira, 1983.

LOURENÇO, Fernando Antonio. Agricultura ilustrada e escravismo nas origens da questão agrária brasileira. Campinas: Unicamp, 2001.

PRADO JÚNIOR, Caio. Formação do Brasil contemporâneo. São Paulo: Brasiliense, 1964.

SANTOS, Roberto Araújo de Oliveira. História econômica da Amazônia, 1800-1920. São Paulo: T. A. Queiroz, 1980.

SANTOS, Rui. Direitos de propriedade fundiária e estratificação social rural: um contributo sociológico. In: GARRIDO, Álvaro; COSTA, Leonor Freire: DUARTE, Luís Miguel (Org.). Estudos em homenagem a Joaquim Romero de Magalhães: economia, instituições e império. Coimbra: Almedina, 2012. 